(C) 2022, The Authors. Published by Elsevier Inc. and Fass Inc. on behalf of the American Dairy Science Association ${ }^{\circledR}$. This is an open access article under the CC BY license (http://creativecommons.org/licenses/by/4.0/).

\title{
Milking system and premilking routines have a strong effect on the microbial community in bulk tank milk
}

\author{
Li Sun, ${ }^{1 *}$ Ase Lundh, ${ }^{1}$ Annika Höjer, ${ }^{2}$ Gun Bernes, ${ }^{3}$ David Nilsson, ${ }^{4}$ Monika Johansson, ${ }^{1}$ Mårten Hetta, ${ }^{3}$ \\ Anders H. Gustafsson, ${ }^{5}$ Karin Hallin Saedén, ${ }^{2}$ and Johan Dicksved ${ }^{6}$ \\ ${ }^{1}$ Department of Molecular Sciences, Swedish University of Agricultural Sciences, Box 7015, SE-750 07 Uppsala, Sweden \\ ${ }^{2}$ Norrmejerier Ek. Förening, Mejerivägen 2, SE-906 22 Umeà, Sweden \\ ${ }^{3}$ Department of Agricultural Research for Northern Sweden, Swedish University of Agricultural Sciences, SE-901 83 Umeå, Sweden \\ ${ }^{4}$ Computational Life Science Cluster, Department of Chemistry, Umeå University, SE-901 87 Umeå, Sweden \\ ${ }^{5}$ Växa Sverige, Ulls väg 26, SE-750 07 Uppsala, Sweden \\ ${ }^{6}$ Department of Animal Nutrition and Management, Swedish University of Agricultural Sciences, Box 7024, SE-750 07 Uppsala, Sweden
}

\begin{abstract}
In this study, we investigated the variation in the microbial community present in bulk tank milk samples and the potential effect of different farm management factors. Bulk tank milk samples were collected repeatedly over one year from 42 farms located in northern Sweden. Total and thermoresistant bacteria counts and $16 \mathrm{~S}$ rRNA gene-based amplicon sequencing were used to characterize microbial community composition. The microbial community was in general heterogeneous both within and between different farms and the community composition in the bulk tank milk was commonly dominated by Pseudomonas, Acinetobacter, Streptococcus, unclassified Peptostreptococcaceae, and Staphylococcus. Principal component analysis including farm factor variables and microbial taxa data revealed that the microbial community in milk was affected by type of milking system. Milk from farms using an automatic (robot) milking system (AMS) and loose housing showed different microbial community composition compared with milk from tiestall farms. A discriminant analysis model revealed that this difference was dependent on several microbial taxa. Among farms using an automatic milking system, there were further differences in the microbial community composition depending on the brand of the milking robot used. On tiestall farms, routines for teat preparation and cleaning of the milking equipment affected the microbial community composition in milk. Total bacteria count (TBC) in milk differed between the farm types, and TBC were higher on AMS than tiestall farms (log 4.05 vs. $\log 3.79$
\end{abstract}

Received April 25, 2021.

Accepted September 7, 2021.

*Corresponding author: li.sun@slu.se
$\mathrm{TBC} / \mathrm{mL}$ for AMS and tiestalls, respectively). Among tiestall farms, milk from farms using a chemical agent in connection to teat preparation and a more frequent use of acid to clean the milking equipment had lower TBC in milk, than milk from farms using water for teat preparation and a less frequent use of acid to clean the milking equipment (log 3.68 vs. $4.02 \mathrm{TBC} / \mathrm{mL}$ ). There were no significant differences in the number of thermoresistant bacteria between farm types. The evaluated factors explained only a small proportion of total variation in the microbiota data, however, despite this, the study highlights the effect of routines associated with teat preparation and cleaning of the milking equipment on raw milk microbiota, irrespective of type of milking system used.

Key words: milking system, premilking routines, bulk tank milk microbiota, microbial community composition

\section{INTRODUCTION}

The microbial community in raw milk is very diverse, with thousands of different taxa present (Quigley et al., 2013), but for obvious reasons pathogens and spoilage bacteria in milk have attracted most attention. Cold storage of milk, both on-farm and at the dairy plant before processing, permits growth of psychrotrophs such as Pseudomonas (De Jonghe et al., 2011). This increases the risk of proteolytic or lipolytic spoilage of dairy products caused by heat-resistant enzymes (Andersson et al., 1981; Stoeckel et al., 2016). Most bacteria and all pathogens are killed during pasteurization of milk, but spore-formers and other heat-resistant bacteria may survive, causing spoilage in different dairy products during processing and storage. Lactic acid bacteria (LAB) in the raw milk do not multiply at refrigeration temperatures and are generally not considered to survive pasteurization in high numbers. However, follow- 
ing heat treatment, some nonstarter lactic acid bacteria (NSLAB; e.g., lactobacilli) have been shown to enter into a viable but nonculturable state in cheese curd (Quigley et al., 2013). The NSLAB are believed to find their way to the cheese from handling and processing of the milk in the dairy plant, but raw farm milk is also suggested to be an important source (Vacheyrou et al., 2011).

A recent study on transfer of bacteria from the environment to raw milk found that most environmental bacteria detected in the milk were also present in the barn and milking parlor environment (Vacheyrou et al., 2011). However, technologically important bacteria such as lactobacilli were rarely found in the barn environment, but were identified in the milk and on the teat surface (Vacheyrou et al., 2011). Monsallier et al. (2012) identified teat skin as an important source of bacteria of technological importance in cheese production, and found that higher counts of Lactobacillus and Enterococcus were associated with a silage-based diet, loose-house systems with straw bedding, and moderate milking hygiene. Hygiene measures in conjunction with milking and effective cleaning of the milking equipment were identified as important factors in determining the balance between bacterial populations in milk in studies by Verdier-Metz et al. (2009) and Michel et al. (2001).

The rapid intensification in dairy production during the past 20 years has resulted in fewer and larger farms with high levels of mechanization (e.g., in feeding) and automation (e.g., use of robotic milking systems; Clay et al., 2020), but also stricter hygienic criteria. The transition in technology and the shift from tiestalls to loose-house systems have undoubtedly had effects on the composition, microbiota, and technological properties of raw milk. A recent study by Priyashantha et al. (2021) reported a strong influence of dairy farm factors (e.g., type of housing and milking system, dominant breed in herd) on quality traits of the bulk tank milk. However, little knowledge is available on the influence of these farm factors on microbial community structure. Therefore, in this study we hypothesized that variation in bacteria counts and microbial community structure in bulk tank milk from commercial farms is related to farm factors, such as breed, technology, and housing system. The aim of the study was to characterize the variation in milk microbiota within and between farms and to identify major on-farm factors influencing the microbial community structure. Because our overall research focus is related to the link between farm factors and the quality and ripening time of a traditional Swedish long-ripening cheese produced in the region, the abundance of LAB in the raw milk was of special interest.

\section{MATERIALS AND METHODS}

\section{Study Design and Milk Sampling}

The study was conducted during the period from February 2016 to February 2017. All dairy farmers delivering milk to the participating cheese-making plant were asked about their willingness to participate in the study, and 42 farmers agreed to participate. Herd and individual animal data (i.e., breed and milk yield) were obtained from the Swedish cow-recording scheme. Information relating to management practices (e.g., systems used for feed production and feeding facilities, housing and milking systems, and routines for milking and cleaning of the equipment) was collected through a questionnaire and farm visits (Priyashantha et al., 2021). Each farm was visited once during the indoor period (February or March) and once in the outdoor period (July).

In Sweden in general, tank milk is collected by the dairy processor every second day. Upon each milk collection, a representative tank milk sample is routinely collected by a device installed on the truck. This sample is transported refrigerated to the official milk testing laboratory (Eurofins Steins laboratory, Jönköping, Sweden), where analysis of milk quality parameters must be initiated within $24 \mathrm{~h}$. One time each in March, May, July, August, October, and December 2016, and in February 2017, an extra 250-mL bottle of tank milk was sampled manually by the truck driver when collecting milk on participating farms. Whereas the routinely collected milk samples were analyzed for total bacteria count (TBC) and thermoresistant bacteria count (TRBC) at the milk testing laboratory, the identical, manually collected tank milk samples were transported at $4^{\circ} \mathrm{C}$ to the Department of Molecular Sciences, Swedish University of Agricultural Sciences for analysis of milk microbiota. Upon arrival, the samples were aliquoted and stored as whole milk at $-80^{\circ} \mathrm{C}$ until analysis. The time from sampling on the farm, to storage at $-80^{\circ} \mathrm{C}$ was maximum $30 \mathrm{~h}$. For various practical reasons, a complete set of samples was not available for all farms for the 7 mo. Therefore, the numbers of farms and farm milk samples have been indicated for each analysis in the results section of this paper.

\section{Participating Farms}

The farms participating in the study were representative for dairy farming in the northern part of Sweden, regarding size, animal material, feeding routines and milking systems. Categorizing the 42 farms according to their milking system, 18 farms used an automatic 
milking system (AMS), 19 used tiestall milking (TIE), and 5 had a milking parlor. All AMS and milking parlor farms had loose housing in which cows were allowed to move freely, with cubicles for resting, whereas all TIE farms with the exception of one (farm 24) had tiestall housing. Farm 24 had loose housing, but the cows were milked in a tiestall. The 18 AMS farms used 2 different brands, with 7 farms using an AMS of brand A and 11 farms of brand B. There are several general differences between the 2 robot brands. Regarding cleaning of the teats, brand A robots have a system whereby the teats are cleaned in washing cups with lukewarm water and then dried by blowing air, whereas brand B robots use 2 parallel rolling brushes to clean the teats. The milking devices and brushes are cleaned between each cow. After milking, 5 of 7 farmers with brand A robots used an iodine-based spray for the teats, as did also about half of those with brand B robots. The rest used either a spray based on lactic acid or no treatment at all.

The cows on the farms were fed grass/clover silage as main forage. Whole-crop silage was also fed on several farms $(\mathrm{n}=10)$. Forage from different cuts (first, second, or third cut) or of different types (grass or clover silage, hay, whole-crop silage) were often mixed and used at the same time. More than half of the farmers $(\mathrm{n}=23)$ had solely round bales for all forage. The rest had either tower $(\mathrm{n}=10)$ or bunker silos $(\mathrm{n}=$ 9) as their main storage system, often in combination with round bales. Additives for preservation of forage was mainly used in the silos [chemical additives, mainly propionic and formic acid ( $\mathrm{n}=17$ farms) or bacterial inoculants ( $\mathrm{n}=3$ farms)]. According to farm visits, hay was used as the major forage on 3 farms at some occasion during the year (farm 9, 11, and 28). Forage comprised on average $60 \%$ of the diet DM. The rest of the diet consisted of a readymade mixed concentrate, or cereals (mostly barley) with a commercial protein concentrate mix. The quality of the water (analyzed for total number of culturable bacteria, Escherichia coli and coliform bacteria, $\mathrm{pH}$, hardness of water, nitrate or nitrite concentration) used to wash the milking equipment was controlled by the dairy cooperative at least once per year. The drinking water to the cows was from the same wells. The most common bedding material was sawdust, which was used on 39 of the 42 farms. Of the remaining 3 farms, one farm used straw, the second peat, and the third used recycled manure solids (farm 23, 13, and 12, respectively). Space per cow was according to the Swedish animal welfare regulations (Jordbruksverket, 2019). According to these regulations, dairy cows in the northern part of the country must have access to pasture at least $60 \mathrm{~d} / \mathrm{yr}$, which mainly occurs during the period of June to August. This was the case on all the studied farms. However, access to pasture varied from mainly offering outdoor activity, to pasture comprising a large part of the daily forage intake. All farms had year-round calving without any obvious seasonal pattern.

\section{Total Bacteria and Thermoresistant Bacteria Count in Milk Samples}

Total bacteria count and TRBC were analyzed in bulk tank milk samples at Eurofins Steins Laboratory (Jönköping, Sweden). The TBC was determined using BactoScan FC (Foss) and TRBC was determined using a culturing method (Wehr et al., 2004).

\section{DNA Extraction of Milk Samples}

Extraction of microbial DNA was performed using a PowerFood DNA isolation kit (Qiagen AB) according to a customized protocol (Sun et al., 2019). In brief, milk samples $(1.8 \mathrm{~mL})$ were thawed at room temperature for $15 \mathrm{~min}$, centrifuged at $13,000 \times g$ for $15 \mathrm{~min}$ at $4^{\circ} \mathrm{C}$, and then incubated on ice for $5 \mathrm{~min}$. The resulting cell pellets with carefully collected fat layer were resuspended in $450 \mu \mathrm{L}$ of MBL buffer (provided with kit). The resuspended mixture was transferred to MicroBead tubes (provided with kit). Cell lysis was conducted by incubating the tubes at $65^{\circ} \mathrm{C}$ for $10 \mathrm{~min}$, after which they were processed in a Fastprep 24 instrument (MP Biomedicals) at 5.0 speed for $60 \mathrm{~s}$, repeated 2 times with a 5 -min pause. The tubes were then centrifuged at $13,000 \times g$ for $15 \mathrm{~min}$ at $4^{\circ} \mathrm{C}$, followed by incubation on ice for $5 \mathrm{~min}$. The supernatant excluding the fat layer was transferred to a new 2 -mL collection tube and the remaining steps were carried out according to the manufacturer's protocol. The resulting DNA was eluted with $50 \mu \mathrm{L}$ of buffer $\mathrm{EB}$ and stored at $-20^{\circ} \mathrm{C}$ until use. The risk of introducing contamination in the laboratory, resulting in misinterpretation of data for samples with low microbial biomass, is obvious, as reported by (Dahlberg et al., 2019). It is therefore important to have careful sample preparation procedures and to include relevant controls. In addition to milk samples, negative DNA extraction controls as well as PCR controls were included by using buffer EB instead of milk.

\section{Illumina Amplicon Library Construction, Sequencing, and Bioinformatic Analysis}

The DNA extracted from the milk samples was used to construct a $16 \mathrm{~S}$ rRNA library with primers $515 \mathrm{~F}$ and 805R (Hugerth et al., 2014). Negative PCR controls and negative DNA extraction controls were both included in the sequencing library. Illumina adaptors and barcode were used for amplification, following a 
2-step PCR approach described previously (Sun et al., 2019). The $16 \mathrm{~S}$ rRNA library was sequenced using the Illumina Miseq platform at SciLifeLab (Uppsala, Sweden) and Macrogen (Seoul, Korea). The raw sequencing data have been deposited to the Sequence Read Archive at the National Center for Biotechnology Information database (http://www.ncbi.nlm.nih.gov/sra), under accession number PRJNA715838. Bioinformatic data processing was performed using Quantitative Insights into Microbial Ecology 2 (Core 2019.04; Bolyen et al., 2019). The raw demultiplexed reads were trimmed using Cutadapt to remove primer sequences (Martin, 2011). Any base from the $3^{\prime}$ end which had quality below 30 was trimmed. A read was discarded if it contained $\mathrm{N}$ base or did not contain primer sequences. The trimmed reads were further processed using DADA2 to de-noise, de-replicate reads, merge pair end reads, and remove chimeras (Callahan et al., 2016), using a truncation length of 210 and $160 \mathrm{bp}$ for forward and reverse reads, respectively. A phylogenetic tree was built using FastTree and MAFFT alignment (Katoh et al., 2002; Price et al., 2010). The SILVA SSU Ref NR 99132 data set was first trimmed to the corresponding primer region and trained as classify-sklearn taxonomy classifier (Pedregosa et al., 2011; Quast et al., 2013; Bokulich et al., 2018). Amplicon sequence variants (ASV) were assigned taxonomy using the resulting classifier. The ASV table was rarefied at 7,139 reads/sample and the core microbiota was computed using the QIIME2 feature-table plugin (Weiss et al., 2017). The weighted UniFrac distance matrix and alpha rarefaction was generated using the QIIME2 diversity plugin (Bolyen et al., 2019).

\section{Statistical Analysis}

The rarefied ASV table and data related to farm management factors were analyzed using SIMCA (Version 14.0.0.1359, Umetrics, Sartorius) and R (https:/ /r-project.org). Principal component analysis (PCA) was performed in SIMCA to analyze the variation in microbial community as influenced by farm factors (see Priyashantha et al., 2021, Supplemental File S1, for the final farm factors that were included in the screening), using standard settings. Orthogonal projections to latent structures discriminant analysis (OPLS-DA) models were cross-validated and the associated measure of predictive performance, $\mathrm{Q}^{2} \mathrm{Y}$, was reported for each model. The cross-validation procedure employed an exclusion strategy where all observations from the same farm were excluded and predicted in the same round. As an additional measure of statistical significance, the $P$-value of the CV-ANOVA diagnostic was determined.
Cross-validation score plots were created for visual assessment of separation between modeled classes. Number of observations (n) and number of variables (K) were reported for each PCA and OPLS-DA model. Amplicon sequence variants with a confidence interval $>0$ and predictive variable importance for the projection (VIP-predictive) $>1$ were used for model interpretation (Galindo-Prieto, 2017). To evaluate differences in TBC and TRBC between type of dairy farming system, a mixed effects linear model was analyzed with the packages lme4, lmerTest, pbkrtest, and emmeans in R, using milking system, brand of AMS robot, acid wash, and teat preparation within TIE system as fixed effect and farm as random effect (Bates et al., 2014; Halekoh and Højsgaard, 2014; Kuznetsova et al., 2017; Lenth, 2021). Both TBC and TRBC data were log-transformed to better fit the normal distribution, resulting in the unit $\log$ bacteria count per milliliter. Differences with $P<$ 0.05 were considered significant.

\section{RESULTS}

\section{Variation in TBC and Microbial Community Within and Between Farms}

The TBC in bulk tank milk samples varied from log 3.48 to $5.00 \mathrm{TBC} / \mathrm{mL}$ over the sampling period, and varied both between and within farms during the period. This is illustrated in Figure 1, where results for farms with data for 5 or more of the 7 selected sampling months are presented. The smallest variation between sampling months was observed in tank milk from farm 24 , with total bacteria counts varying from $\log 3.85$ / $\mathrm{mL}$ to $\log 3.95 / \mathrm{mL}$. The largest variation was found in milk from farm 40, with bacteria counts varying from $\log 3.48$ to $\log 4.76 \mathrm{TBC} / \mathrm{mL}$.

The 16S rRNA gene sequencing yielded an average of 35,299 (median 26,866) sequences per sample. The sequences were distributed in 3,096 ASV, representing 194 taxonomic families and 464 genera. One particular ASV (68f648), classified as Pseudomonas, was found in negative DNA extractions, negative PCR controls, and milk samples. Because Pseudomonas is commonly identified as part of the natural microbial community in raw milk, it is difficult to distinguish natural occurrence of this ASV from contamination. To limit the potential risk of this ASV heavily influencing the data analysis, milk samples with relative abundance (RA) $>10 \%$ of this ASV were removed from the analysis. In total, 15 bacterial genera were found to represent a core microbiota, present in at least $90 \%$ of the bulk tank milk samples (Table 1). The 5 most dominant bacteria overall in tank milk samples were Pseudomonas, Aci- 


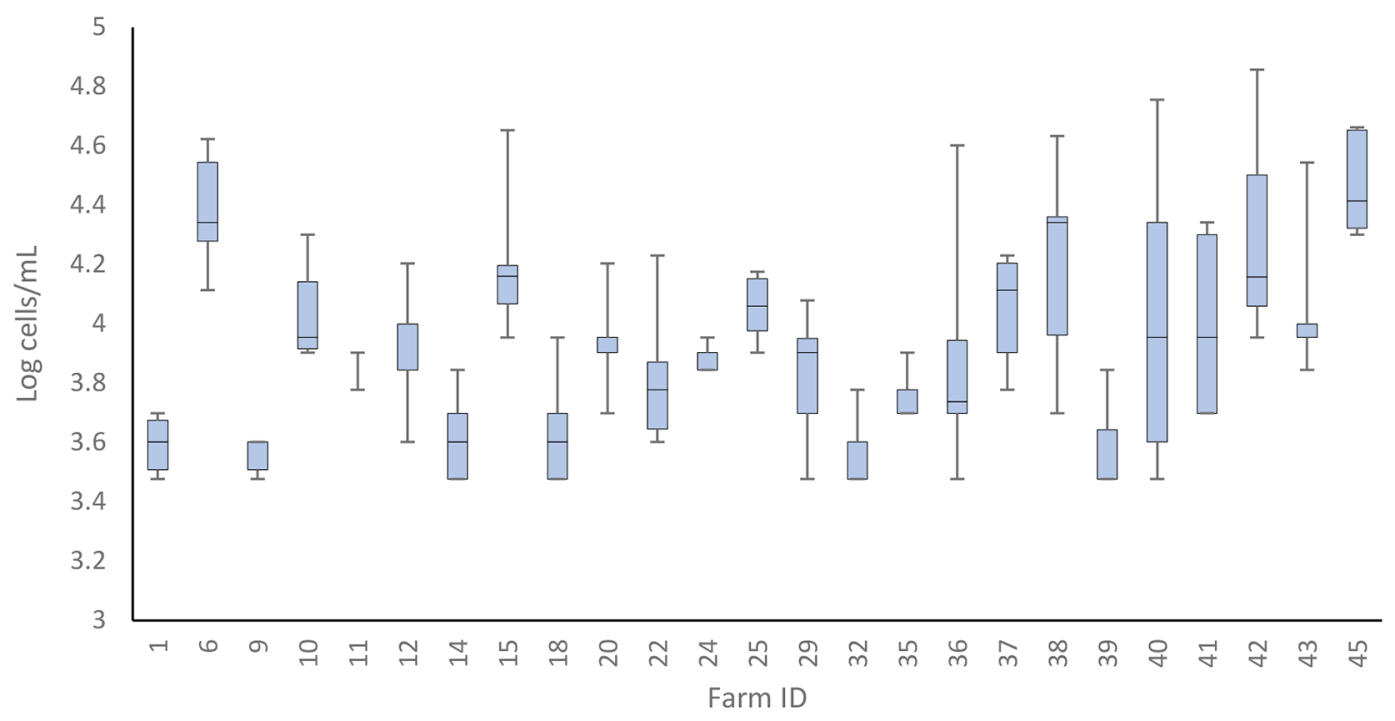

Figure 1. Box plot showing the total number of bacteria $(\log$ cells $/ \mathrm{mL})$ in bulk tank milk samples from participating farms. Only the data for farms represented by at least 5 milk sampling occasions are shown. The horizontal bars through the boxes show the median (i.e., the 50 th percentile) of the distance bacterial distribution. The lower and upper extents of the boxes indicate the 25th and 75 th percentiles of the distribution, respectively. The upper and lower whiskers indicate the maximum and minimum values, respectively. The detection limit is 1,000 cells/ $\mathrm{mL}$. In the case of farm 11, the variation in total bacteria number was very low between the different samples, explaining the absence of a box. In this case, the lower bar shows the median, and the upper bar is the upper whisker.

netobacter, Streptococcus, unclassified Peptostreptococcaceae, and Staphylococcus.

Assessment of microbial community stability in milk over time, using weighted UniFrac matrix comparison, revealed variation within individual farms (Figure 2A). Most of the farms showed heterogeneous community composition in milk over the different sampling occasions, whereas a few farms had quite stable community structure. As indicated by the homogeneity comparison (Figures 2A and 2B; Supplemental Figure S1, https:/ /doi.org/10.7910/DVN/OL0ASF), the microbial community was sometimes similar and sometimes varied substantially within the same farm across different sampling occasions. The dominant genera also varied between farms. For instance, farms 1, 11, and 45 showed little variation across the different milk sampling occasions (Figure 2A), but Acinetobacter dominated in milk on all sampling occasions for farm 45, whereas multiple genera instead of a single genus dominated on all sampling occasions for farms 1 and 11 (Figure 2B). In milk from farms showing greater variation between sampling occasions (e.g., farms 18 and 22; Figure 2A), the dominant genera varied to a larger extent (Figure 2B). Although the effect of season was not within the scope of this study, it was evaluated during the initial screening of the data. Data showed that the seasonal effect was not interfering with the relationships studied in the 3 OPLS-DA models. Instead, the effect of season was clearly observed in other model components, such as the fifth principal component (PC) for the larger data set $(n=210)$ used for analysis of the influence of farm factors and also in some of the orthogonal components of the OPLS-DA models.

\section{Differences in Microbial Community Between Farms as Influenced by Farm Management Factors}

Differences in Microbial Community Associated with Milking System. The influence of different farm factors on the microbial community in bulk tank milk was initially screened using PCA, with number of observations, $\mathrm{n}=210$, and number of variables, $\mathrm{K}=$ 228 (see Supplemental File S1 of Priyashantha et al., 2021). The PCA identified milking system and type of housing as the 2 most influential factors. As mentioned, all AMS and milking parlor farms had loose housing, whereas all TIE farms except farm 24 had tiestall housing. Thus, dairy farms were categorized according to milking system, being aware that these categories also included the effects of confounded factors, of which the individual effects could not be distinguished within this study. Milk from farms using AMS and from farms a using tiestall milking system showed 2 clear clusters in the PCA, separated along PC 2, whereas milk from farms with milking parlors showed a wider distribution in the plot (Figure 3). In subsequent comparisons, we therefore decided to focus on differences between the 2 dominant farm types, distinguished as farms using 


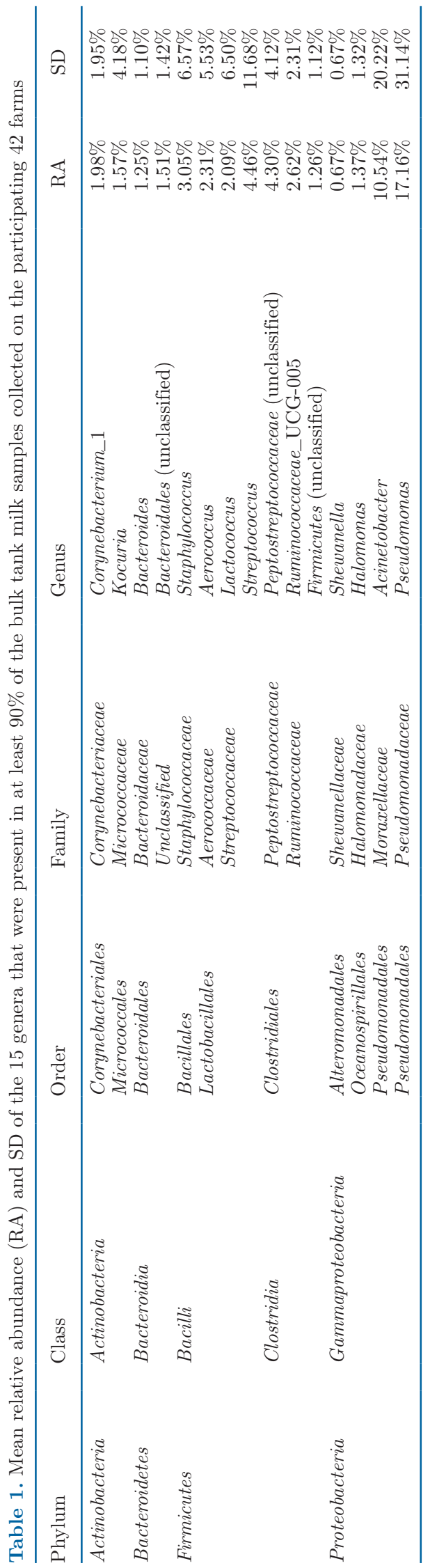

AMS and farms using tiestall milking. Mixed effects linear model analysis revealed that TBC was higher in milk from the AMS farms $(\log 4.05 \mathrm{TBC} / \mathrm{mL})$ than in milk from the TIE farms $(\log 3.79 \mathrm{TBC} / \mathrm{mL}, P<0.01$; Table 2). There was no significant difference in TRBC between the AMS and TIE farms. Interestingly, the rarefaction curves of observed ASV revealed a higher number in milk from AMS farms than in milk from TIE farms (Figure 4A).

An OPLS-DA model $\left(\mathrm{n}=185, \mathrm{~K}=227, \mathrm{Q}^{2} \mathrm{Y}=\right.$ $0.688, P<0.001)$ was created for assessing the difference in ASV between milk from AMS and TIE farms (Supplemental Figure S2, https://doi.org/10.7910/ DVN/OL0ASF). Of the $41 \mathrm{ASV}$ that were found to differ between the farm types, 15 showed higher RA in milk from TIE farms (Figure 5). The remaining 26 ASV were present in higher RA in milk from AMS farms. It is interesting to note that several ASV classified into the same genus or family showed different dominance in milk from either AMS or TIE farms. For instance, within the genus Corynebacterium, ASV cee9ed showed higher RA in milk from TIE farms, whereas ASV bad597 and 0c35e6 showed higher RA in milk from AMS farms. Similarly, Aerococcaceae_d347bc, Psychrobacter_83c81d, Corynebacteriaceae_700739, and Acinetobacter_b994ec were present in higher RA in milk from TIE farms, whereas Aerococcaceae_1bbfc6, Psychrobacter_24a457, Corynebacteriaceae_db47e9, Acinetobacter_189aec, and Acinetobacter_f2f4ab showed higher RA in milk from AMS farms. Among the 15 ASV with higher RA in milk from TIE than AMS farms, Pseudomonas_69d9bd was identified as the most dominant ASV. Lactobacillus_c9822d, which belongs to the NSLAB, showed higher RA in milk from TIE than in milk from AMS farms. The genus Kocuria and family Enterobacteriaceae were represented by 2 ASV each (303143 and be6f97 for Kocuria; 26d8f0 and fc5860 for Enterobacteriaceae). Of the 26 ASV with higher RA in milk from AMS than in milk from TIE farms, 2 ASV (598071 and bd2ebc) were classified to the same genus (Streptococcus) and 3 ASV (3ca58b, 464a52, and 69a95a) were classified to the same family (Peptostreptococcaceae). In addition, Bacilli_38162e, Lactobacillales_c34a7c, Atopostipes_89db65, Carnobacteriaceae_0b711b, Aerococcus_81618b, Facklamia_83534c, and Firmicutes_dacd87 showed higher RA in milk from AMS farms than in milk from TIE farms (Figure 5).

Differences in Microbial Community Between AMS Farms Using Different Brands of Robots. Among the AMS farms, the most influential factor for microbial community composition in tank milk was the brand of milking robot, with PCA ( $\mathrm{n}=95, \mathrm{~K}=202)$ plots indicating clear clusters of milk samples repre- 
senting farms with brand A and B robots, respectively, along PC 2 (Figure 6). Analysis of TBC and TRBC levels revealed no significant differences between the
2 brands of milking robots, but farms with a brand A robot had a higher number of observed ASV than farms with a brand B robot (Figure 4B).
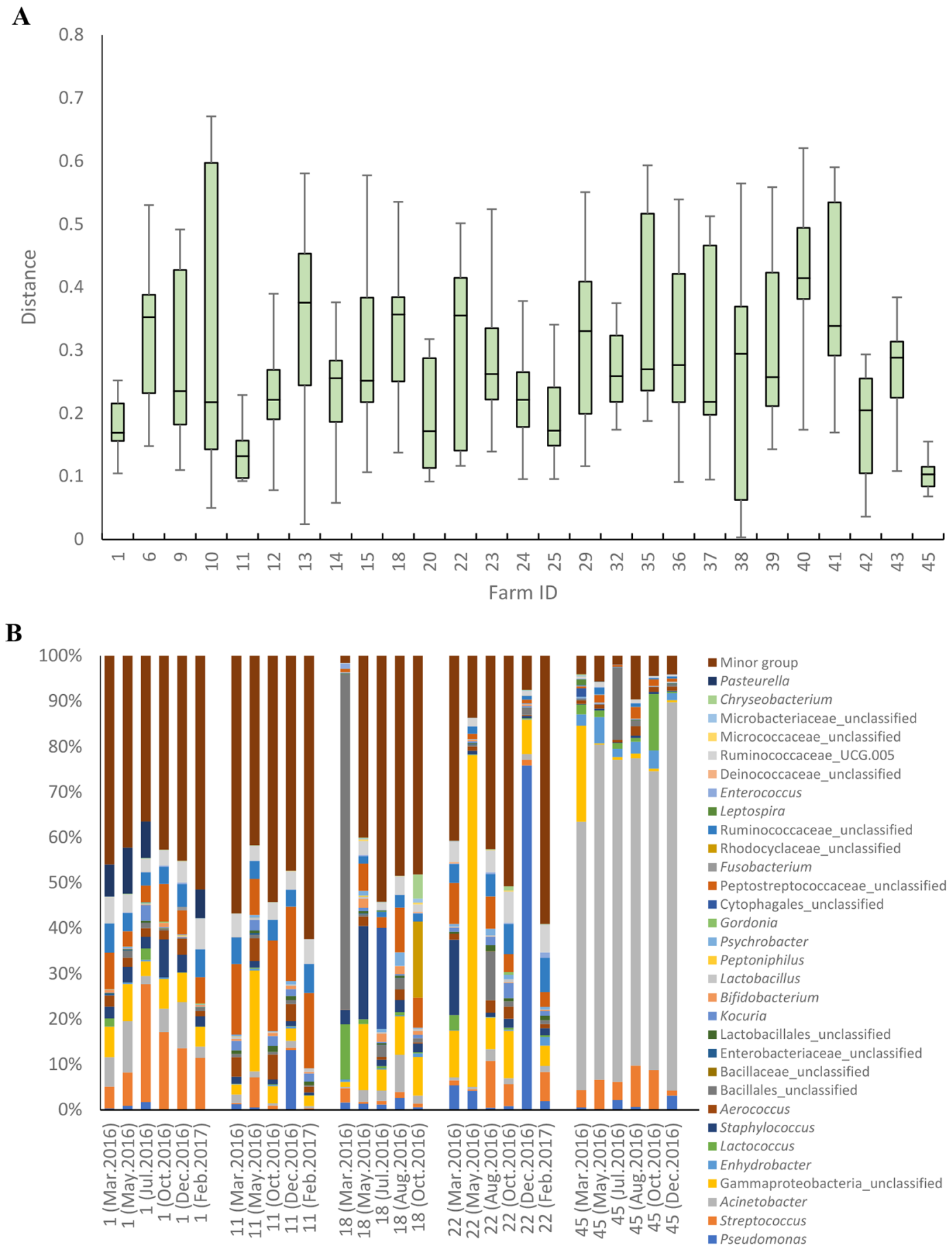

Figure 2. (A) Boxplots showing the distribution of weighted UniFrac distance matrix data between bulk tank milk samples from individual farms for which results from at least 5 sampling occasions were available. The horizontal bars through the boxes show the median (i.e., the 50th percentile) of the distance matrix distribution. The lower and upper extents of the boxes are the 25th and 75th percentiles of the distribution, respectively. The lower and upper whiskers in the box plots are the minimum and maximum values of the distribution, respectively. (B) Relative abundance (RA, \%) of dominant genera in bulk tank milk samples from some of the participating farms; farm ID followed by sampling month. Genera with maximum RA less than $10 \%$ were grouped together (minor group). 


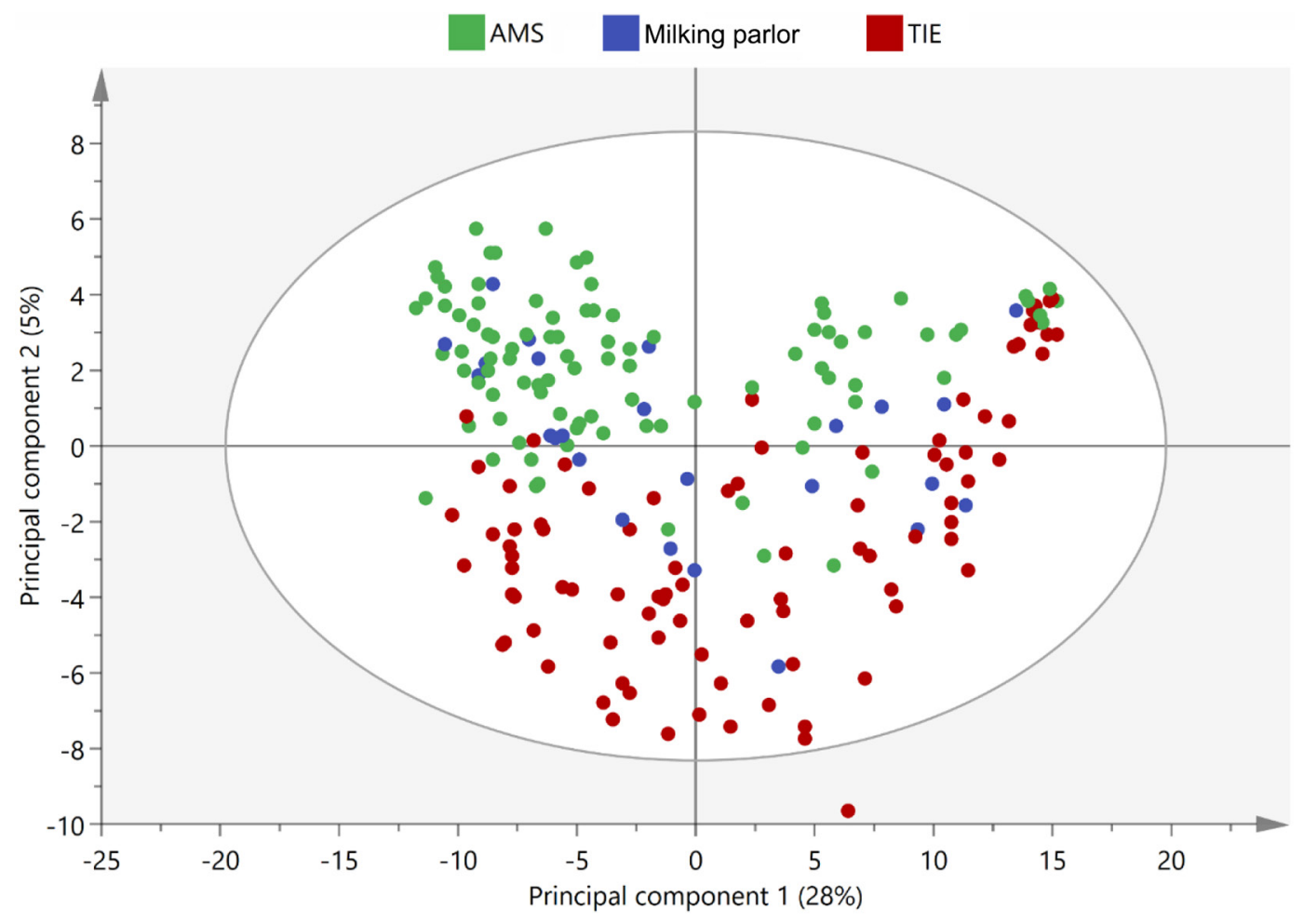

Figure 3. Principal component analysis of microbial taxa in bulk tank milk samples collected on farms using automatic milking (AMS), milking parlor, or tiestall milking (TIE) systems. Each dot represents a unique milk sample from an individual farm, colors indicating type of farm as represented by milking system. The milk samples originated from 18, 5, and 19 farms with AMS, milking parlor, or TIE milking systems, respectively.

An OPLS-DA model $\left(\mathrm{n}=95 ; \mathrm{K}=204 ; \mathrm{Q}^{2} \mathrm{Y}=0.607\right.$, $P<0.001)$ was created to assess the difference between AMS with different brands of milking robots and to identify ASV contributing to the difference (Supplemental Figure S3, https://doi.org/10.7910/DVN/
OL0ASF). Among the 18 ASV identified, 17 showed higher RA in milk from farms with a brand A milking robot and only one ASV, Ralstonia_c021db, showed higher RA in milk from farms with a brand B milking robot (Figure 7). Among the ASV present in higher RA

Table 2. Mean values of log-transformed total and thermoresistant bacteria counts in bulk tank milk from farms characterized according to their milking systems [i.e., automatic milking system (AMS) and tiestall milking systems (TIE)] ${ }^{1}$

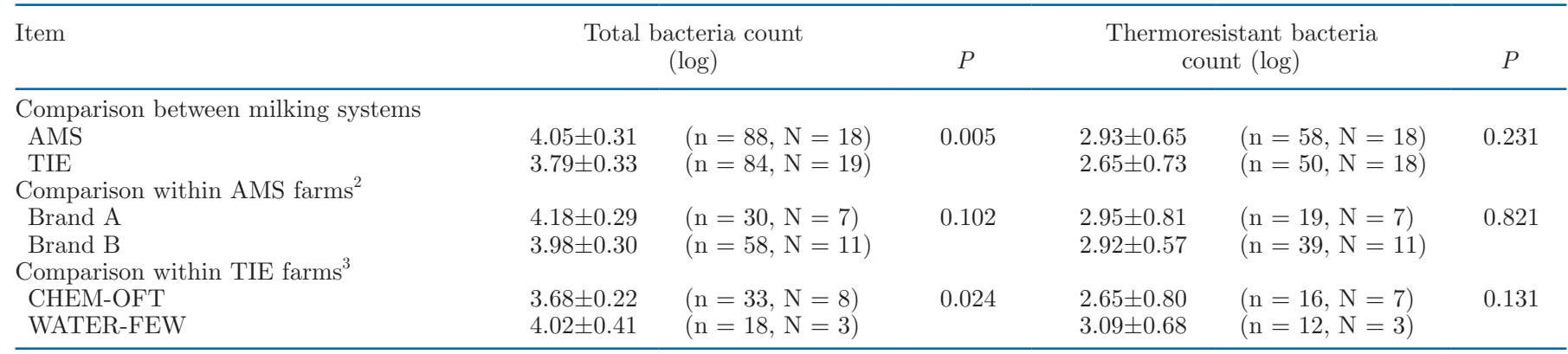

${ }^{1}$ Within the group of AMS farms, values were compared between farms with different brand of milking system. Within the oroup of TIE farms, values were compared between farms with different routines related to preparation of teats before milking and cleaning of the milking equipment. $\mathrm{n}=$ number of bulk tank milk samples; $\mathrm{N}=$ number of farms.

${ }^{2}$ Within AMS farms, 2 different brands of robots were used (i.e., brand A and brand B).

${ }^{3}$ Within TIE farms, different routines related to preparation of teats before milking and cleaning of the milking equipment could be distinguished: CHEM-OFT = farms using a chemical (CHEM) agent for teat preparation before milking as well as a more frequent use (OFT) of acid wash to clean the milking system (confounded factors); WATER-FEW = farms using only water for teat preparation before milking and a less frequent (FEW) use of acid to clean the milking system (confounded factors). 

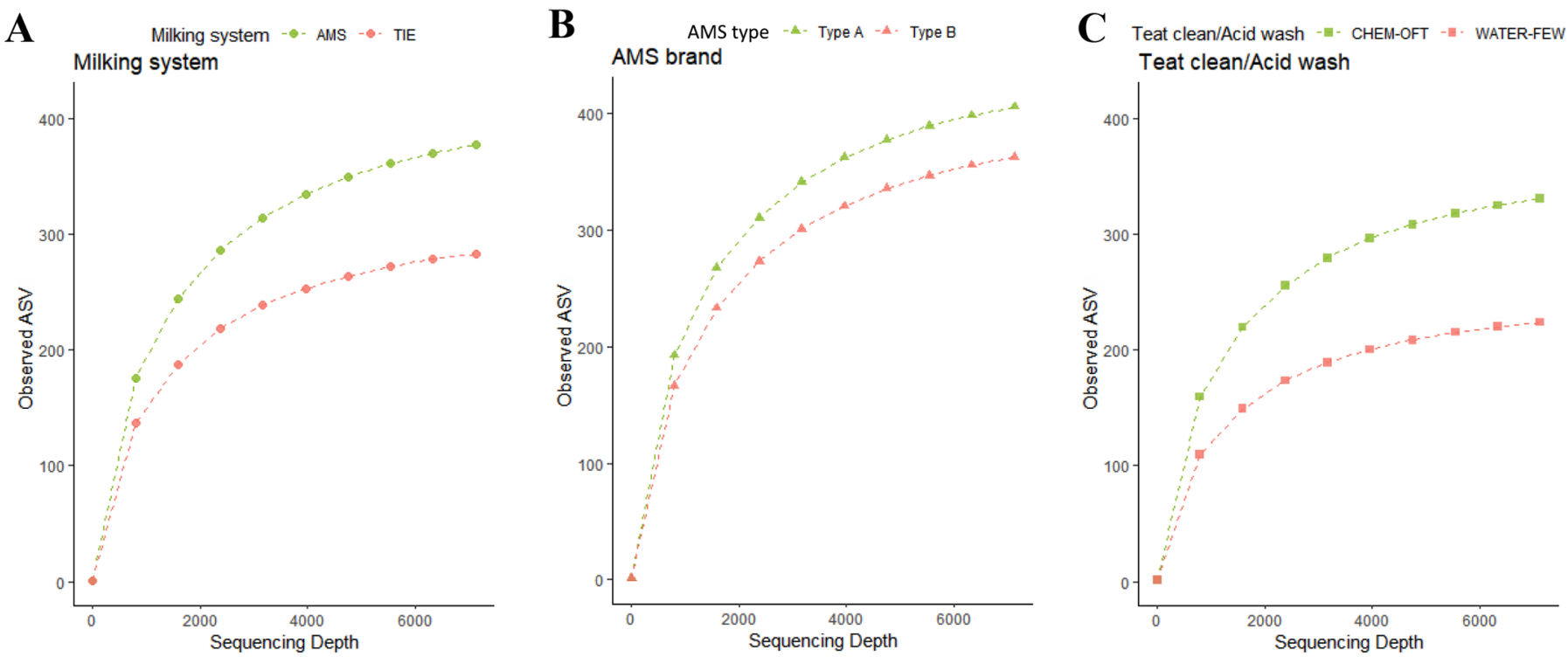

Figure 4. (A) The rarefaction curves of observed amplicon sequence variants (ASV) in milk, comparing bulk tank milk samples from herds with different milking systems [represented by 95 and 90 bulk tank milk samples originating from 18 farms using automated milking systems (AMS) and 19 farms using tiestall milking (TIE), respectively]; (B) the rarefaction curves of observed ASV in milk, comparing bulk tank milk samples from AMS farms using different brands of AMS (represented by 32 and 63 bulk tank milk samples originating from 7 farms using brand A and 11 farms using brand B, respectively); (C) the rarefaction curves of observed ASV in milk comparing bulk tank milk samples from TIE farms with different routines related to cleaning of the milking equipment (frequency of acid to alkaline wash) and method for teat cleaning (represented by 34 milk samples originating from 8 farms using a chemical agent in connection to teat cleaning and frequent use of acid to clean the milking equipment (CHEM-OFT), and 19 milk samples originating from 3 farms using water only to clean teats before milking and less frequent use of acid to clean the milking equipment (WATER-FEW).

in milk from farms with a brand A robot, Lactococcus and Acinetobacter were the 2 most frequently identified genera, with 2 (cc1f55 and d90ee6) and 5 ASV (189aec, 90c1ff, a35537, 9defed, and 000d0f), respectively. In addition, Streptococcus_5cac9e, Lactobacillales_3ebdbc, Atopostipes_568dfd, and Carnobacteriaceae_0b711b were observed at higher RA in milk from AMS farms using a brand A milking robot, although these LAB only constituted minor populations.

Differences in Microbial Community Between Tiestall Farms Using Different Routines for Teat Preparation and Cleaning of the Milking Equipment. Within the TIE farms, the variation in management factors was larger than for the AMS farms. For example, some TIE farms reported using a cloth to clean teats before milking, whereas other farms used paper towels. Likewise, some TIE farms reported premilking directly onto the floor, whereas others premilked into a dedicated cup. Some TIE farms did not have automatic removal of the milking clusters as an option in their milking system, whereas others had. Among the management factors evaluated (Priyashantha et al., 2021), the frequency of applying acid or alkaline wash to descale and clean the milking equipment, and the procedure used for teat preparation before milking gave the largest separation of samples in terms of microbial community structure in tank milk samples in the PCA plot $(\mathrm{n}=90, \mathrm{~K}=222)$. However, these 2 factors were clearly confounded, because TIE farms using acid wash less frequently also more commonly used only water, or used a dry cloth or paper towel, when preparing the teats before milking. In contrast, TIE farms that applied acid wash more frequently (every second wash) more commonly reported use of chemical agents for teat preparation. TIE farms with no or less frequent acid washing of their milking equipment (varying from once every second day to once per week or more seldom) and nonchemical-based teat preparation were more associated with the left side of the PCA plot (Figure 8).

In subsequent comparisons of farms with tiestall milking, we therefore decided to focus on the differences between the farms that used chemicals during teat preparation and more frequently used acid wash to clean the milking equipment (CHEM-OFT), and the farms that employed water and less frequent acid washing of the milking equipment (WATER-FEW). The average TBC in tank milk from WATER-FEW farms was $\log 4.02 \mathrm{TBC} / \mathrm{mL}$, compared with $\log 3.68$ $\mathrm{TBC} / \mathrm{mL}$ in milk from the CHEM-OFT group (Table 2, $P<0.05)$. Contrary to expectations, there was no significant difference between the 2 groups in numbers 
of thermoresistant bacteria in the milk. The number of observed ASV was higher in milk from the CHEMOFT group than in milk from the WATER-FEW group (Figure 4C).

An OPLS-DA model $\left(\mathrm{n}=53, \mathrm{~K}=220, \mathrm{Q}^{2} \mathrm{Y}=0.784\right.$, $P<0.001)$ was created for assessing differences in ASV between milk from the 2 groups of tiestall farms (Supplemental Figure S4, https://doi.org/10.7910/
DVN/OL0ASF). Of the $22 \mathrm{ASV}$ identified as the most important taxa in the model, 11 ASV showed higher RA in milk from the CHEM-OFT group, whereas the remaining 11 showed higher RA in milk from the WATER-FEW group (Figure 9). Two ASV, cc1f55 and d90ee6, that had higher RA in WATER-FEW milk were classified into the same genus (Lactococcus). Similarly, 2 ASV, 44e039 and fc5860, classified

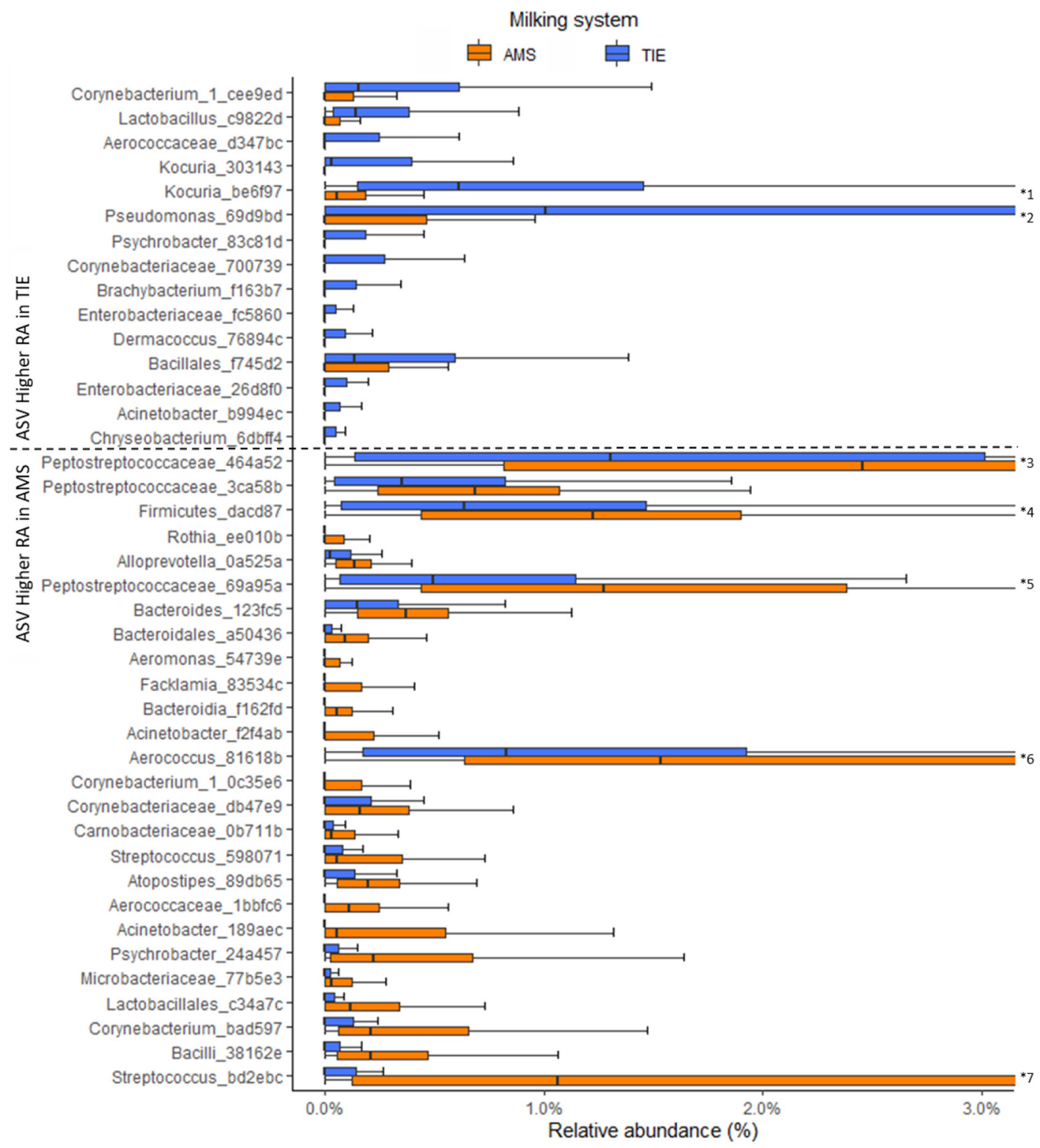

Figure 5. The relative abundance (RA, \%) of amplicon sequence variants (ASV) in bulk tank milk samples from farms using automated milking systems (AMS) and tiestall milking systems (TIE), respectively. The vertical bar through the box is the median (i.e., the 50th percentile) value. The left and right extents of the box are the 25th and 75th percentiles (q3) of the values, respectively, and the left and right whiskers of the box plot represent the minimum and maximum values of the distribution. There are 95 and 90 milk samples originated from the 18 and 19 farms that using AMS and TIE respectively. For ASV outside the axis limit: *1: TIE whisker 3.4\%; ${ }^{*} 2$ TIE q3 12\%, TIE whisker 30\%; ${ }^{*} 3$ : AMS q3 $4.2 \%$, AMS whisker $8.6 \%$, TIE q3 3.0\%, TIE whisker $7.2 \%$; $*$ : AMS whisker $3.5 \%$, TIE whisker3.3\%; ${ }^{*} 5$ : AMS whisker $5.1 \%$; $* 6$ : AMS q3 $3.3 \%$, AMS whisker 7.0\%, TIE whisker 4.4\%; *7: AMS q3 4.5\%, AMS whisker 11\%. 


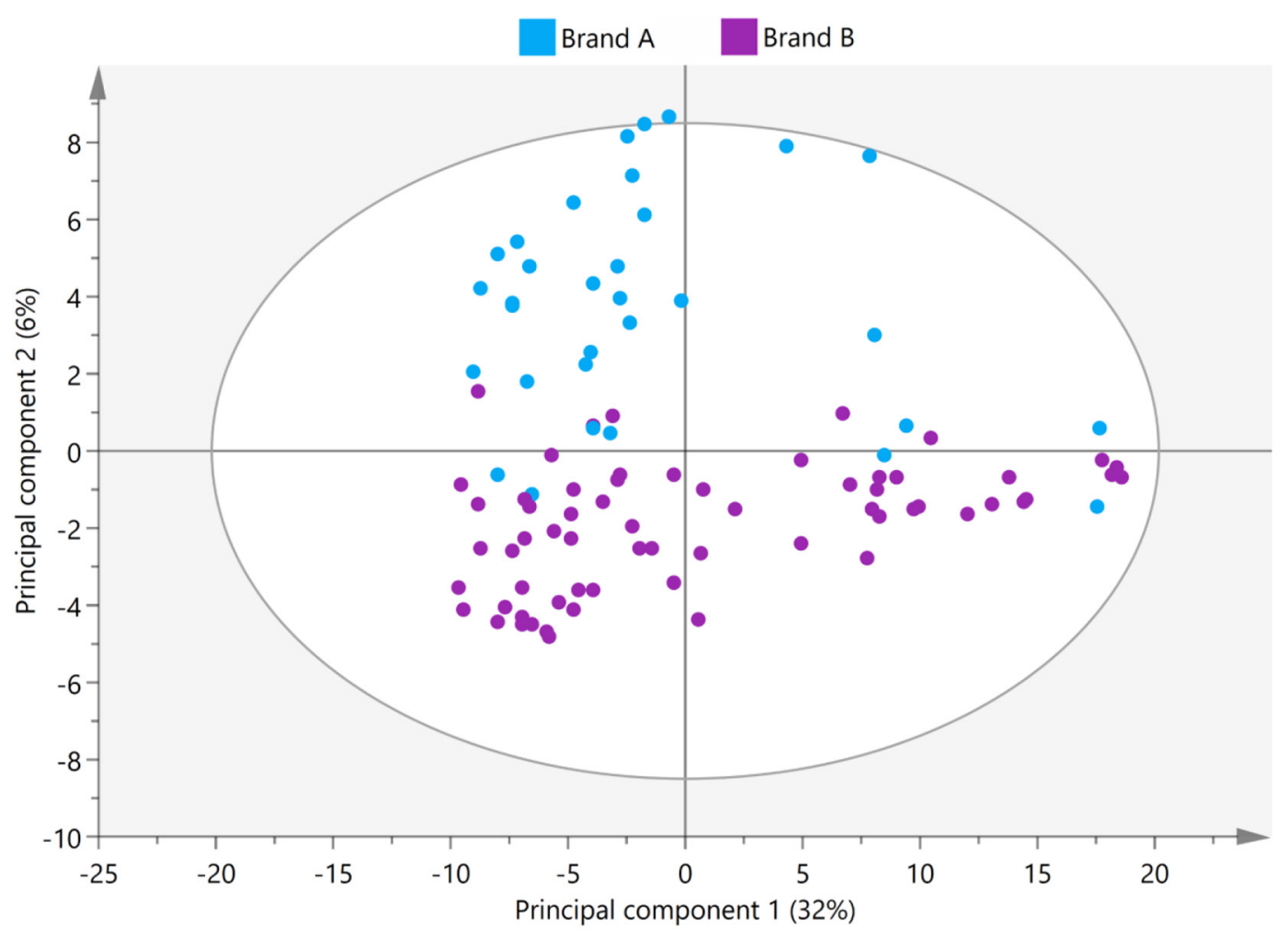

Figure 6. Principal component analysis plot of microbial data for bulk tank milk samples collected on farms with automatic milking systems (AMS). Each dot represents a milk sample from an individual farm, colors indicating brand of AMS. Numbers of farms using brand A and B were 7 and 11, respectively, and the number of bulk tank milk samples associated with the 2 brands of robots were 32 and 63 , respectively.

as Enterobacteriaceae showed higher RA in milk from the WATER-FEW group. The genera Acinetobacter and Corynebacterium were identified in milk from both groups, with higher RA of Acinetobacter_66a959 and Corynebacterium_1_c2eea2 in milk from the WATERFEW group and higher RA of Acinetobacter_90c1ff and Corynebacterium_bad597 in milk from the CHEMOFT group. It is worth noting that one individual farm, farm 42, was responsible for the observed differences in ASV between farm groups, including the previously mentioned $4 \mathrm{ASV}$ from Lactococcus and Enterobacteriaceae and one additional ASV, Bacillaceae_bed463. Lactobacillales_9cbacb, with higher RA in milk from the WATER-FEW group, was also mainly represented by one farm (farm 15). Within the samples from the CHEM-OFT group, Leuconostoc_0c7492 and Weissella_e9f4ea showed higher RA than in milk from WATER-FEW farms, although these 2 LAB were present at low RA $(<1 \%)$.

\section{DISCUSSION}

In this study we explored the microbial community in tank milk from 42 Swedish dairy farms, using samples collected over the course of one year. The aim was to learn more about the composition and temporal dynamics of the microbial community and to identify the most important farm factors in shaping microbial community composition in tank milk. The study was conducted in a region of Sweden where the milk is used for production of long-ripening cheese, so we were particularly interested in the abundance of technologically important NSLAB in the raw milk.

The core microbiota in the tank milk consisted of 15 genera, of which the 5 most abundant were Pseudomonas, Acinetobacter, Streptococcus, unclassified Peptostreptococcaceae, and Staphylococcus (Table 1). A recent Norwegian study also identified Pseudomonas, Streptococcus, Acinetobacter, and Staphylococcus as being among the most abundant bacterial genera in tank milk from 45 farms (Skeie et al., 2019). In the Norwegian study, tank milk was stored refrigerated for $3 \mathrm{~d}$ on participating farms, in our study for $2 \mathrm{~d}$, before milk was collected by the milk truck. Because cold storage of raw milk is known to permit growth of Gram-negative psychrotrophic bacteria, such as Pseudomonas and Acinetobacter, it was not surprising to find these genera among the most abundant in our study and also in the 
study by Skeie et al. (2019). However, this is not always the case, because Breitenwieser et al. (2020) found that Staphylococcus, Corynebacterium, Caryophanon, and Streptococcus were the dominant genera in farm milk samples that had been stored at refrigerated temperature for 2 and 3 consecutive days before sampling. Although Pseudomonas and Acinetobacter were dominant genera in tank milk in our study, genera other than psychrotrophs were more abundant in milk from some farms (see examples in Figure 2B).

\section{Variation in Tank Milk Microbiota Within and Between Farms}

The TBC in tank milk was generally low, ranging from $\log 3.48$ to $5.00 \mathrm{TBC} / \mathrm{mL}$, indicating high hygiene quality and farms respecting the European limits for TBC in raw milk (i.e., log 5.00 bacteria/mL milk; European Commission, 2004). The TBC were in line with the $\log 3.6$ to $5.28 \mathrm{TBC} / \mathrm{mL}$ reported in the Norwegian study cited above (Skeie et al., 2019). However, the TBC profile in milk from the individual farms varied (Figure 1). Some farms showed low counts on all sam- pling occasions, whereas numbers in milk from other farms fluctuated over the sampling period and on some farms bacteria counts in milk remained at relatively high levels. In contrast to O'Connell et al. (2015), who reported a seasonal trend in monthly average TBC, with TBC being greatest at the beginning and end of the year, we did not observe any general trend in TBC related to milk sampling month or season.

The results also revealed that the temporal dynamics of bulk tank milk microbiota (i.e., the variation in microbial community structure) varied between the participating farms (Figure 2A). Some farms showed relatively large variation in microbial community structure despite low TBC (e.g., farms 18 and 22). Farms 1 and 45 , on the other hand, both showed high homogeneity of the milk microbiota, although farm 1 delivered milk with low TBC and farm 45 delivered milk with relatively high TBC on all occasions. Other farms, such as farms 1 and 11, were characterized by low TBC and low variation in microbial community structure over time but showed relatively high alpha diversity (i.e., with no single dominant bacterial genus). Among the farms that showed large variation in community struc-

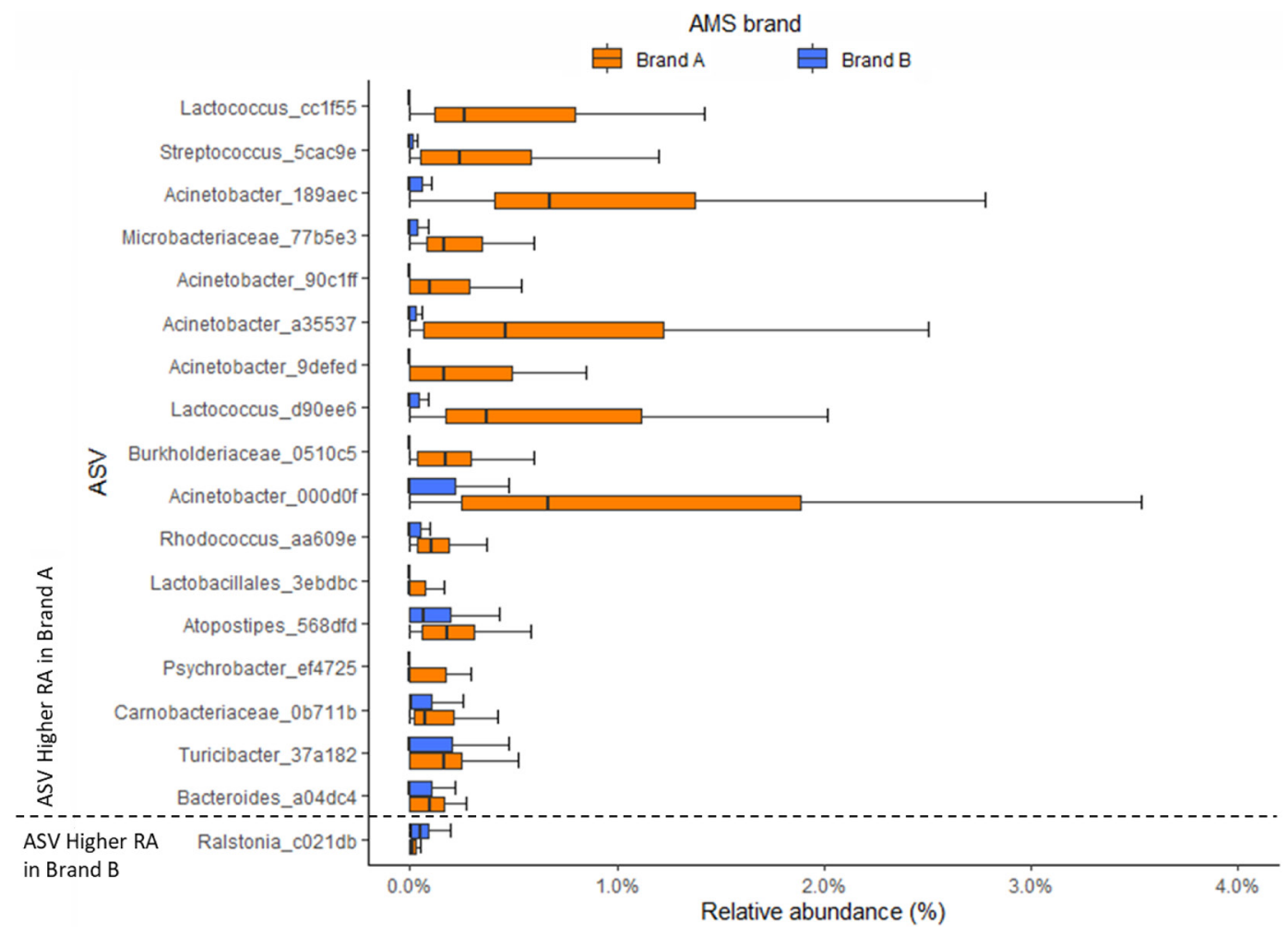

Figure 7. The relative abundance (RA, \%) of amplicon sequence variants (ASV, bacterial taxa followed by ASV numbers) in bulk tank milk samples from farms using automatic milking systems (AMS) of brand A and B, respectively. The vertical bars through the boxes are the median (i.e., the 50th percentile) values. The left and right extents of the boxes are the 25 th and 75 th percentiles of the values, respectively. The left and right whiskers of the boxes are the minimum and maximum values of the distribution, respectively. There are 32 and 63 milk samples originating from 7 and 11 farms using AMS brands A and B, respectively. 


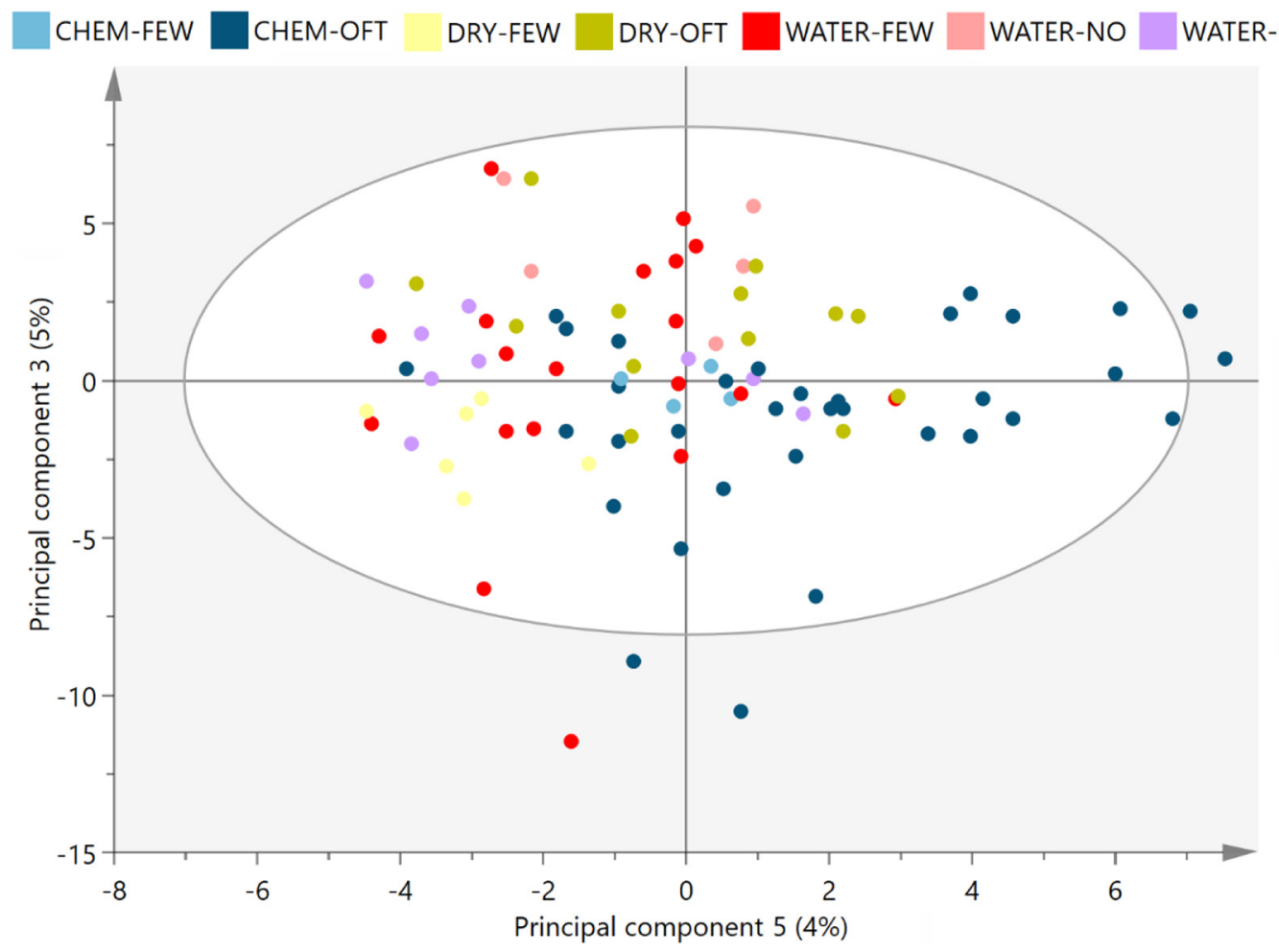

Figure 8. Principal component analysis plot of microbial data in bulk tank milk samples from tiestall farms only. Each point represents a bulk tank milk sample from an individual farm. Routines used to prepare teats before milking were as follows: CHEM $=$ use of chemical agent in teat preparation, DRY = no liquid-based method for teat preparation, WATER = use of water only to prepare teats before milking. Frequency of acid wash to clean the milking equipment was as follows: FEW = less frequent use of acid wash (from once every second day to once per week or less frequently); $\mathrm{NO}=$ never use acid wash, only use alkaline wash; OFT = frequent use of acid wash (every second wash).

ture between the different sampling occasions, there was no systematic pattern in the variation (e.g., no seasonal trend). To our knowledge, the temporal variation in microbial community structure in bulk tank milk over longer periods has not been widely investigated. Although the season effect was not in the scope of this paper, it was investigated during the initial, general analysis of the data. We found that the seasonal effect was not interfering with the relationships studied in the 3 OPLS-DA models. Instead, the effect of season was clearly observed in other model components, such as the fifth PC for the larger data set. Also Skeie et al. (2019) reported that microbial composition in tank milk from the same farm varied significantly between sampling occasions. In their study, milk samples from individual farms were collected on 3 occasions, with 2 to $3 \mathrm{wk}$ between each sampling occasion. Overall, the TBC was similar between the 3 samplings from each individual farm, but the milk microbiota varied between the collection days. Several factors, such as changes in feed quality, farm environment, weather conditions, and animal health, might have contributed to these changes (Skeie et al., 2019).

\section{Influence of Different Farm Factors on Farm Milk Microbiota}

The OPLS-DA models presented in this study had $\mathrm{Q}^{2} \mathrm{Y}$ values ranging from 0.607 to 0.784 , indicating strong model performance. This was also seen in the cross-validated score plots where the different farm types were found to be nearly nonoverlapping. The strong model performance could partly be attributed to a sufficiently large sample size, enabling reliable loading interpretations from significant models. Although several samples originated from each farm, causing a possible redundancy in the data, the cross-validation procedure effectively mitigated this, as all observations from the same farm were excluded and predicted in the same cross-validation round.

The PCA identified type of dairy farm, categorized according to milking system, as the most influential factor for the milk microbiota. A clear difference in milk microbiota between AMS and tiestall farms was observed, whereas the milk microbiota from farms with a milking parlor could not be separated from the other 2 systems. However, this clustering was linked to PC 2, 


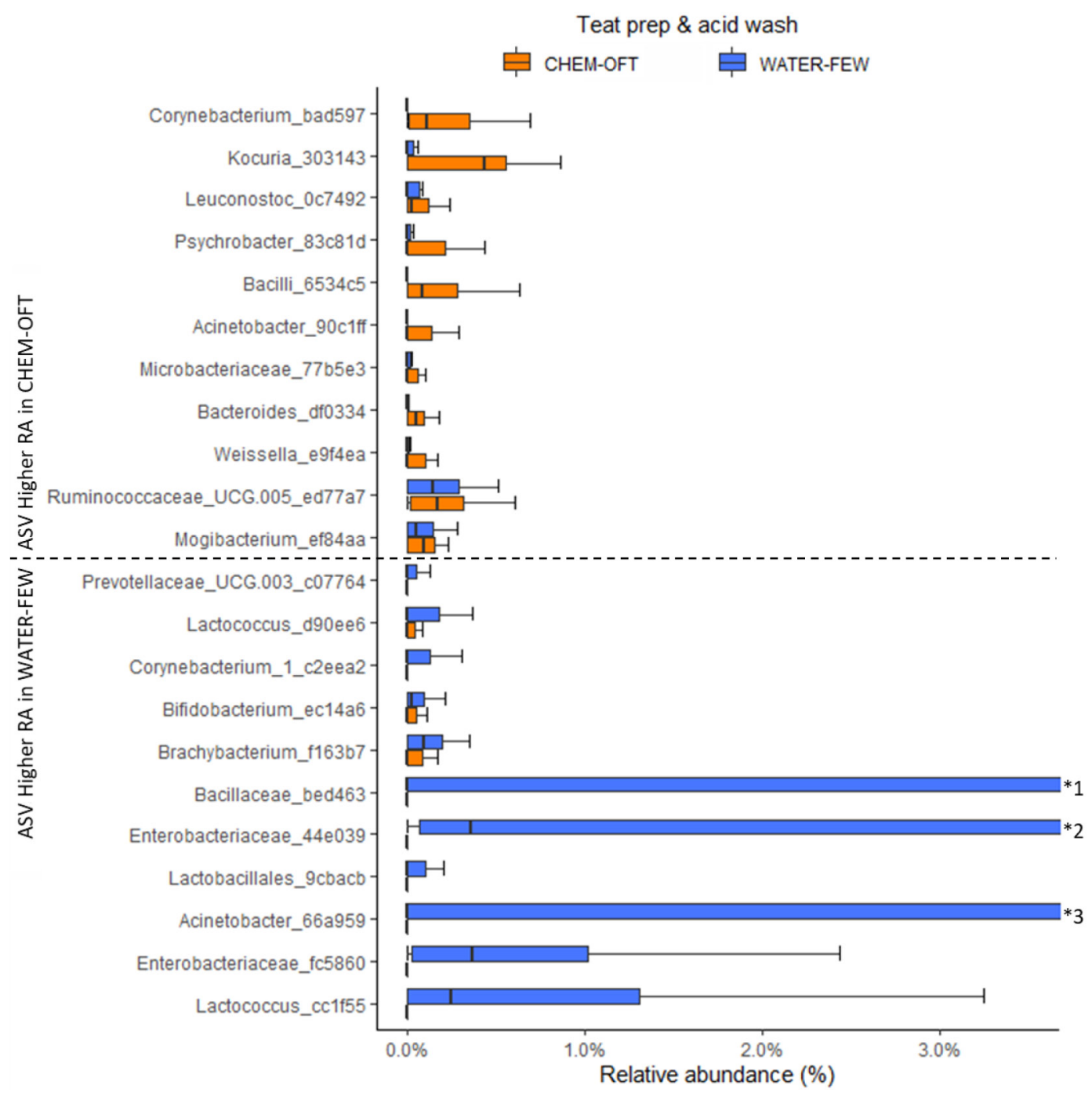

Figure 9. Relative abundance (RA, \%) of amplicon sequence variants (ASV, bacterial taxa followed by ASV number) in bulk tank milk samples from tiestall farms grouped according to method for preparation of teats before milking and frequency of acid wash to clean the milking equipment. CHEM-OFT consisted of farms that used chemicals in connection to teat preparation and more frequently (every second wash) applied acid solution to clean the milking equipment (34 milk samples originated from 8 farms); WATER-FEW consisted of farms that used water for teat cleaning and less frequently (from once every second day to once per week) applied acid solution to clean the milking equipment (19 milk samples originated from 3 farms). The vertical bars through the boxes are the 50th percentile values. The left and right extents of the boxes are the 25 th and 75 th percentiles (q3) of the values, respectively. The left and right whiskers of the boxes are the minimum and maximum values of the distribution, respectively. *1: WATER-FEW q3 28\%, WATER-FEW whiskers 57\%; *2: WATER-FEW q3 5.4\%, WATER-FEW whiskers $13 \%$; *3: WATER-FEW q3 14\%, WATER-FEW whiskers $17 \%$.

which explained only $5 \%$ of the variation in the data. Several confounding factors, such as housing and milking system, breed, and number of cows, contributed to the characterization of the 2 major farm types in our study (i.e., AMS and tiestall farms, respectively). The influence from the confounded farm factors could not be distinguished and should not be overlooked. Moreover, effects of some individual factors might have been hidden or masked, due to low frequency among the farms. To study the influence of individual factors, a case-study or a controlled trial might give better results than screening of factors, which this study was aiming for. Milk from tiestall farms showed higher RA, especially of Pseudomonas_69d9bd, whereas bacteria from Peptostreptococcaceae and Ruminococcaceae, commonly found in dairy cow feces samples, were more abundant in milk from AMS farms.

In agreement with expectations and with findings in a previous review by Hogenboom et al. (2019), we found that levels of TBC were higher in tank milk from AMS farms than in milk from farms with a tiestall milking system $(P<0.01)$. An increase in TBC is in most cases 
associated with shortcomings in the teat preparation process. Teat skin is reported to be the major source of bacteria for milk microbiota, even more important than environmental sources, such as feces, bedding material, and milking equipment (Vacheyrou et al., 2011). In a study examining the microbial communities in raw cow milk and potential transfer from the barn environment to the milk, Vacheyrou et al. (2011) found that coryneforms were commonly associated with teat skin, whereas some cocci, such as Staphylococcus, were very common in the environment, and others, such as Lactococcus and Enterococcus, were found only in the milk. Differences in microbial community composition between teat skin and milk samples, with higher proportions of Corynebacterium on teat skin than in milk, were also found in a study by Dahlberg et al. (2020). Skeie et al. (2019) concluded that milking system and on-farm management practices have a great effect on the bacterial composition of milk, with milk from AMS farms showing higher TBC than milk from farms using a milking parlor. They attributed those differences to inferior washing of the teat, lack of a drying step before milking, and challenges with equipment cleaning in AMS. A study by Christiansson et al. (1999) on factors affecting the number of Bacillus cereus spores in raw milk during the grazing period found that the spore content of milk was strongly associated with degree of soil contamination on the teats, but that the number of spores could be reduced by teat cleansing. The influence of teat preparation on microbial community composition in milk was also investigated by Doyle et al. (2016), who concluded that the teat surface was the most significant source of contamination of the milk. In agreement with previous studies, within each of the 2 farm types of our study (i.e., AMS and tiestall milking), differences in milk microbiota were seen between farms using different cleaning procedures before milking. Tank milk from the 2 brands of milking robots represented (A, B) showed clear clustering, although only a small proportion of the variation in the data was explained by the model. Five ASV belonging to the genus Acinetobacter, but also some LAB, Lactococcus, and Streptococcus, were more abundant in milk from brand A robots. This difference in milk microbiota was most likely attributable to differences in the procedure used for teat preparation before milking. Brand A robots have a system whereby teats are cleaned in washing cups with lukewarm water and then dried by blowing air, whereas brand B robots use 2 parallel rolling brushes to clean the teats. For the farms with tiestall milking, routines for teat preparation were largely confounded by the frequency of use of acid wash to clean the equipment. Nevertheless, these factors influenced the microbial community in tank milk, with some bacteria, such as Enterobacteriaceae, Lactococcus, and Bacillaceae, being more abundant in milk from tiestall farms that only used water for teat preparation and less frequently used acid wash to clean their milking equipment.

Interestingly, milk from AMS farms was associated with higher species richness than milk from tiestall farms. Skeie et al. (2019) suggested that differences in herd size could have contributed to observed differences in microbial diversity between milk samples collected from the farms in their study. Considering that the first source of bacterial contamination in milk is the individual cow, farms with more cows could show greater microbial diversity in the tank milk. There was a clear difference in average herd size between AMS (85 cows) and TIE (30 cows) farms in our study (data not shown; for details see Priyashantha et al., 2021), which could have contributed to the differences in microbial diversity between the herd types. Comparing the microbial diversity in milk from AMS farms using different brands of milking robots, milk from farms using brand A robots (teats prepared in washing cups with lukewarm water, dried by blowing air) showed higher species richness than milk from farms using brand $\mathrm{B}$ robots (Figure 4B). In comparison with milk from AMS farms, milk from tiestall farms was associated with lower TBC and higher RA of Pseudomonas, where the latter could be an additional explanation for lower species richness. Unlike on AMS farms, on tiestall farms higher species richness was associated with lower TBC $(P<0.05)$, represented by milk from farms using chemical agents in teat preparation in combination with more frequent use of acid wash. One explanation could be that the higher TBC in milk from farms with less frequent use of acid wash, and no chemical agents in teat preparation, was associated with a few dominant bacterial taxa, including Bacillaceae, Enterobacteriaceae, and Acinetobacter, contributing to lower species richness. However, it is important to note that the differences between tiestall farms using different routines for cleaning equipment and teat preparation were observed in PC3 and PC5. Moreover, because fewer milk samples were available for comparison within tiestall farms, the findings should be treated with caution and require further validation.

Pseudomonas is commonly found in milk, and it was therefore difficult to determine whether the particular ASV Pseudomonas $68 \mathrm{f} 648$ observed in this study originated from the milk or was introduced during laboratory analysis of the milk samples. As a precautionary strategy, we removed samples with high abundance of this $\mathrm{ASV}(>10 \% \mathrm{RA})$, which eliminated its potential contaminating effect on the data set. Moreover, in discriminant analysis this particular ASV did not 
contribute to the outcomes of this study, including the observed differences linked to farm type, milking equipment, and teat cleaning method.

\section{CONCLUSIONS}

Differences in teat preparation before milking most likely contributed to the differences in tank milk microbiota observed between types of farms (AMS vs. tiestall farms) and within farm types. However, the variation in microbiota data explained by milking system, robot brand, and routines used for teat preparation and cleaning the milking equipment was limited, and most could not be explained by the models. The routines used on tiestall farms, (i.e., CHEM-OFT and WATER-FEW) displayed a weaker association to the microbial data than milking system (AMS or TIE) or robot brand (A or B). The microbial community in tank milk reflects events taking place in the herd and routines associated with milking and handling of the milk. It is challenging to predict or control this microbial community, but modifying the routines associated with teat preparation and cleaning of the milking equipment, irrespective of type of milking system used, could provide some degree of control.

\section{ACKNOWLEDGMENTS}

This study was conducted with financial support from the Swedish Farmers' Foundation for Agricultural Research (Stockholm, Sweden), the Kamprad Family Foundation (Växjö, Sweden), the Regional Fund for Agricultural Research in Northern Sweden (Uppsala, Sweden), and the Faculty of Natural Resources and Agriculture, SLU (Uppsala, Sweden). We thank all the dairy farmers who participated in the study. The authors have not stated any conflicts of interest.

\section{REFERENCES}

Andersson, R. E., G. Danielsson, C. B. Hedlund, and S. G. Svensson. 1981. Effect of a heat-resistant microbial lipase on flavor of ultrahigh-temperature sterilized milk. J. Dairy Sci. 64:375-379. https:/ /doi.org/10.3168/jds.S0022-0302(81)82581-7.

Bates, D., M. Mächler, B. Bolker, and S. Walker. 2014. Fitting linear mixed-effects models using lme4. J. Stat. Softw. 67:1-48. https:// doi.org/10.18637/jss.v067.i01.

Bokulich, N. A., B. D. Kaehler, J. R. Rideout, M. Dillon, E. Bolyen, R. Knight, G. A. Huttley, and J. G. Caporaso. 2018. Optimizing taxonomic classification of marker-gene amplicon sequences with QIIME 2's q2-feature-classifier plugin. Microbiome 6:90. https:// doi.org/10.1186/s40168-018-0470-z.

Bolyen, E., J. R. Rideout, and M. R. Dillon. 2019. Reproducible, interactive, scalable and extensible microbiome data science using QIIME 2. Nat. Biotechnol. 37:852-857. https://doi.org/10.1038/ s41587-019-0209-9.
Breitenwieser, F., E. V. Doll, T. Clavel, S. Scherer, and M. Wenning. 2020. Complementary use of cultivation and high-throughput amplicon sequencing reveals high biodiversity within raw milk microbiota. Front. Microbiol. 11:1557.

Callahan, B. J., P. J. McMurdie, M. J. Rosen, A. W. Han, A. J. A. Johnson, and S. P. Holmes. 2016. DADA2: High-resolution sample inference from Illumina amplicon data. Nat. Methods 13:581-583. https://doi.org/10.1038/nmeth.3869.

Christiansson, A., J. Bertilsson, and B. Svensson. 1999. Bacillus cereus spores in raw milk: Factors affecting the contamination of milk during the grazing period. J. Dairy Sci. 82:305-314. https://doi .org/10.3168/jds.S0022-0302(99)75237-9.

Clay, N., T. Garnett, and J. Lorimer. 2020. Dairy intensification: Drivers, impacts and alternatives. Ambio 49:35-48. https://doi.org/10 $.1007 / \mathrm{s} 13280-019-01177-y$.

Dahlberg, J., L. Sun, K. Persson Waller, K. Östensson, M. McGuire, S. Agenäs, and J. Dicksved. 2019. Microbiota data from low biomass milk samples is markedly affected by laboratory and reagent contamination. PLoS One 14:e0218257. https://doi.org/10.1371/ journal.pone.0218257.

Dahlberg, J., J. E. Williams, M. A. McGuire, H. K. Peterson, K. Östensson, S. Agenäs, J. Dicksved, and K. P. Waller. 2020. Microbiota of bovine milk, teat skin, and teat canal: Similarity and variation due to sampling technique and milk fraction. J. Dairy Sci. 103:7322-7330. https://doi.org/10.3168/jds.2019-17783.

De Jonghe, V., A. Coorevits, K. Van Hoorde, W. Messens, A. Van Landschoot, P. De Vos, and M. Heyndrickx. 2011. Influence of storage conditions on the growth of Pseudomonas species in refrigerated raw milk. Appl. Environ. Microbiol. 77:460-470.

Doyle, C. J., D. Gleeson, P. W. O'Toole, and P. D. Cotter. 2016. Impacts of seasonal housing and teat preparation on raw milk microbiota: A high-throughput sequencing study. Appl. Environ. Microbiol. 83:e02694-16. https://doi.org/10.1128/AEM.02694-16.

European Commission. 2004. Regulation (EC) No. 854/2004 of the European Parliament and of the Council of 29 April 2004 laying down specific rules for the organisation of official controls on products of animal origin intended for human consumption. Off. J. Eur. Union L 139:55-205.

Galindo-Prieto, B. 2017. Novel variable influence on projection (VIP) methods in OPLS, O2PLS, and OnPLS models for single- and multi-block variable selection. Doctoral thesis. Department of Chemistry, Industrial Doctoral School, Umeå University, Sweden.

Halekoh, U., and S. Højsgaard. 2014. A Kenward-Roger approximation and parametric bootstrap methods for tests in linear mixed models: The R package pbkrtest. J. Stat. Softw. 59:1-32.

Hogenboom, J. A., L. Pellegrino, A. Sandrucci, V. Rosi, and P. D'Incecco. 2019. Invited review: Hygienic quality, composition, and technological performance of raw milk obtained by robotic milking of cows. J. Dairy Sci. 102:7640-7654. https://doi.org/10 .3168/jds.2018-16013.

Hugerth, L. W., H. A. Wefer, S. Lundin, H. E. Jakobsson, M. Lindberg, S. Rodin, L. Engstrand, and A. F. Andersson. 2014. DegePrime, a program for degenerate primer design for broad-taxonomic-range PCR in microbial ecology studies. Appl. Environ. Microbiol. 80:5116-5123.

Jordbruksverket. 2019. Statens jordbruksverks föreskrifter och allmänna råd om nötkreaturshållning inom lantbruket (Constitution No. SJVFS 2019:18, Saknr L 104). ISSN: 1102-0970. Jordbruksverk.

Katoh, K., K. Misawa, K.-i. Kuma, and T. Miyata. 2002. MAFFT: a novel method for rapid multiple sequence alignment based on fast Fourier transform. Nucleic Acids Res. 30:3059-3066. https://doi .org/10.1093/nar/gkf436.

Kuznetsova, A., P. B. Brockhoff, and R. H. Christensen. 2017. lmerTest package: Tests in linear mixed effects models. J. Stat. Softw. 82:1-26.

Lenth, R. V. 2021. emmeans: Estimated marginal means, aka leastsquares means. R package version 1.5.4. https://CRAN.R-project .org $/$ package $=$ emmeans . 
Martin, M. 2011. Cutadapt removes adapter sequences from highthroughput sequencing reads. EMBnet.journal. 17:10-12. https:/ /doi.org/10.14806/ej.17.1.200.

Michel, V., A. Hauwuy, and J.-F. C. J. Lait. 2001. La flore microbienne de laits crus de vache: Diversité et influence des conditions de production. Le Laite INRA Ed. 81:575-592.

Monsallier, F., I. Verdier-Metz, C. Agabriel, B. Martin, and M.-C. Montel. 2012. Variability of microbial teat skin flora in relation to farming practices and individual dairy cow characteristics. Dairy Sci. Technol. 92:265-278. https://doi.org/10.1007/s13594-012 -0064-7.

O'Connell, A., S. McParland, P. L. Ruegg, B. O'Brien, and D. Gleeson. 2015. Seasonal trends in milk quality in Ireland between 2007 and 2011. J. Dairy Sci. 98:3778-3790. https://doi.org/10.3168/jds 2014-9001.

Pedregosa, F., G. Varoquaux, A. Gramfort, V. Michel, B. Thirion, O. Grisel, M. Blondel, P. Prettenhofer, R. Weiss, and V. Dubourg. 2011. Scikit-learn: Machine learning in Python. J. Mach. Learn. Res. 12:2825-2830.

Price, M. N., P. S. Dehal, and A. P. Arkin. 2010. FastTree 2 - Approximately maximum-likelihood trees for large alignments. PLoS One 5:e9490. https://doi.org/10.1371/journal.pone.0009490.

Priyashantha, H., Å. Lundh, A. Höjer, G. Bernes, D. Nilsson, M. Hetta, K. H. Saedén, A. H. Gustafsson, and M. Johansson. 2021. Composition and properties of bovine milk: A study from dairy farms in northern Sweden; Part I. Effect of dairy farming system. J. Dairy Sci. 104:8582-8594. https://doi.org/10.3168/jds.2020-19650.

Quast, C., E. Pruesse, P. Yilmaz, J. Gerken, T. Schweer, P. Yarza, J. Peplies, and F. O. Glöckner. 2013. The SILVA ribosomal RNA gene database project: Improved data processing and web-based tools. Nucleic Acids Res. 41(Database issue):D590-D596. https:// doi.org/10.1093/nar/gks1219.

Quigley, L., O. O'Sullivan, C. Stanton, T. P. Beresford, R. P. Ross, G. F. Fitzgerald, and P. D. Cotter. 2013. The complex microbiota of raw milk. FEMS Microbiol. Rev. 37:664-698. https://doi.org/10 1111/1574-6976.12030.

Skeie, S. B., M. Håland, I. M. Thorsen, J. Narvhus, and D. Porcellato. 2019. Bulk tank raw milk microbiota differs within and between farms: A moving goalpost challenging quality control. J. Dairy Sci. 102:1959-1971. https://doi.org/10.3168/jds.2017-14083.

Stoeckel, M., M. Lidolt, T. Stressler, L. Fischer, M. Wenning, and J. Hinrichs. 2016. Heat stability of indigenous milk plasmin and proteases from Pseudomonas: A challenge in the production of ultrahigh temperature milk products. Int. Dairy J. 61:250-261. https:/ /doi.org/10.1016/j.idairyj.2016.06.009.

Sun, L., J. Dicksved, H. Priyashantha, Å. Lundh, and M. Johansson. 2019. Distribution of bacteria between different milk fractions, investigated using culture-dependent methods and molecularbased and fluorescent microscopy approaches. J. Appl. Microbiol. 127:1028-1037. https://doi.org/10.1111/jam.14377.

Vacheyrou, M., A.-C. Normand, P. Guyot, C. Cassagne, R. Piarroux, and Y. Bouton. 2011. Cultivable microbial communities in raw cow milk and potential transfers from stables of sixteen French farms. Int. J. Food Microbiol. 146:253-262. https://doi.org/10 .1016/j.ijfoodmicro.2011.02.033.

Verdier-Metz, I., V. Michel, C. Delbès, and M.-C. Montel. 2009. Do milking practices influence the bacterial diversity of raw milk? Food Microbiol. 26:305-310. https://doi.org/10.1016/j.fm.2008.12 .005 .

Wehr, H. M., J. F. Frank, and A. P. H. Association. 2004. Standard methods for the examination of dairy products. American Public Health Association.

Weiss, S., Z. Z. Xu, S. Peddada, A. Amir, K. Bittinger, A. Gonzalez, C. Lozupone, J. R. Zaneveld, Y. Vázquez-Baeza, A. Birmingham, E. R. Hyde, and R. Knight. 2017. Normalization and microbial differential abundance strategies depend upon data characteristics. Microbiome 5:27. https://doi.org/10.1186/s40168-017-0237-y. 